\title{
0 ator no processo colaborativo do Teatro da Vertigem
}

\author{
Miriam Rinaldi
}

\section{Autoria}

autoria no processo colaborativo do Teatro da Vertigem é um assunto complexo, uma vez que há um paradoxo inerente à questão. Esse paradoxo começa pelo autor do texto que resulta desse processo. Pois, se por um lado o dramaturgo não é o único produtor do material e, portanto, não é o autor exclusivo da obra, pois seu trabalho é a reunião de materiais de diversos autores, por outro é sua a assinatura do texto escrito que resulta do processo. Assim sendo, ele deve ter plena determinação sobre suas escolhas, mesmo que estas tenham como consequiência inúmeras reescrituras do texto, a partir das críticas e das sugestôes dos outros criadores. É o que reconhece Fernando Bonassi, dramaturgo do terceiro espetáculo do Teatro da Vertigem, "Apocalipse 1, 11", estreado no Presídio do Hipódromo, em São Paulo, em 2000. Em entrevista à autora, Bonassi observa que "com a experiência do Teatro da Vertigem eu não me sinto à vontade para assinar o texto. Porque eu sou autor de algumas coisas e os atores de outras. Cada um é responsável pelo que cria, no bom e no mau sentido". ${ }^{1}$

No processo colaborativo do Teatro da Vertigem, a discussão da autoria não se liga exclusivamente à construção do texto escrito. $\mathrm{Na}$ fala do light designer Guilherme Bonfanti, por exemplo, percebemos a idéia de que essa autoria se dá por uma espécie de filtragem: "Eu acredito na minha autoria dessa forma: compartilhada. Num certo momento, com todo mundo, e aí é um campo aberto para todo mundo interferir e trazer sugestões. Mas como sou eu quem vai processar, organizar e finalizar, a autoria se dá aí nesse lugar”. ${ }^{2}$

Do ponto de vista dos atores, a questão não deixa de ser delicada. É frustrante perceber que, das inúmeras proposições apresentadas no processo, nada foi selecionado, ou ainda ver que uma personagem, uma fala ou mesmo uma imagem foram cortadas. Pode ser mais frustrante ainda quando essa criação passa a ter o corpo e a voz de outro ator. Tomemos como exemplo o caso da figura Talidomida do Brasil, proposta em workshop por Mariana Lima e interpretada

Miriam Rinaldi é atriz do Teatro da Vertigem e professora do Curso de Artes do Corpo da PUC-SP e mestranda do PPG em Artes Cênicas da ECA-USP.

1 Fernando Bonassi em entrevista realizada pela autora em 17.02.1999.

2 Guilherme Bonfanti em entrevista realizada pela autora em 14.02.2005. 
no espetáculo por Luciana Schwinden, que dá um depoimento sobre sua personagem: "A minha Talidomida não tem nada a ver com a Talidomida da Mariana. Ela trouxe a idéia, que era muito forte, mas o meu desenho de Talidomida não tem nada a ver com o desenho dela. Depois disso veio o texto da Constituição, que é do Bonassi. A frase "Me leva pra casa..." é minha e surgiu do próprio desconforto da cena, quando vocês (audiência) começaram a rir."3

A partir do exemplo acima, podemos perceber que a autoria no processo colaborativo não está relacionada apenas à gênese dos materiais, mas à forma como eles se processam e se transformam. No contínuo jogo de dar e receber que acontece entre os atores, existe uma operação autoral de apropriação. Se por um lado esse processo exige desapego do ator - postura inerente a todos os artistas em processo colaborativo -, que deve aceitar o corte da cena bem escrita ou mesmo da personagem não realizada, por outro deve ter disponibilidade de fazer da idéia do outro a sua própria. A generosidade é imprescindível em qualquer posição que se ocupe.

$\mathrm{Se}$, a partir de certo ponto de vista, pode ser decepcionante para o ator não realizar suas próprias idéias, por outro lado pode ser provocativo vê-las executadas por outro ator, pois elas acabam por ganhar volume na multiplicidade das visões do grupo, uma vez que a "solução de um problema é a somatória de todas as contribuições" ${ }^{4} \mathrm{O}$ que se percebe é que os materiais se transformam e se enriquecem no livre trânsito entre os criadores.

A colocação do ator nesse lugar de trânsito, de pensar não apenas sua personagem, mas também a obra em seu todo, é um dos fundamentos do processo colaborativo. Nesse proces- so, o ator não está na ponta ou na base da produção artística, mas participa ativamente da circulação dos materias. Conhecer a origem desses materiais, participar de sua produção e sua transformação, promover critérios de escolha são alguns dos procedimentos que fazem dos atores autores do trabalho.

No entanto, é preciso reconhecer que a autoria no processo colaborativo está localizada numa zona de fronteira, de acordos delicados e tensos, pois tenta lidar com as exigências do coletivo, ao mesmo tempo que reclama o reconhecimento individual. Trata tanto da autoria de grupo, à medida que todos são criadores e agentes de múltiplas apropriações e transformações, quanto da autoria particular, que acontece quando determinado artista opera a reunião, a filtragem ou a organização dos materiais apresentados pelo coletivo.

\section{Workshop}

No Teatro da Vertigem, o workshop é a mais efetiva expressão autoral dos atores em processo colaborativo. Denominamos workshop uma cena criada pelo ator em resposta a uma pergunta ou um tema lançados em sala de ensaio. ${ }^{5}$

Talvez Richard Schechner tenha sido um dos primeiros criadores a definir o procedimento. Para Schechner, workshop é uma fase ativa de pesquisa no processo de criação da performance, em que o artista tem liberdade de explorar diversas possibilidades em ensaios. É o espaço da experimentação por excelência, em que se chega à produção de protótipos (Schechner, 2003, p. 198-200). Mas a maior referência nesse tipo de procedimento que, em geral, usa per-

Luciana Schwinden em entrevista realizada pela autora em 16.02.2005.

4 Fala de Sérgio Siviero, em "O que fazemos em Sala de ensaio". Teatro da Vertigem, Trilogia Bíblica. São Paulo: Publifolha, 2002, p. 47.

5 Até aqui esse é o procedimento mais praticado entre os atores. Nada impede, no entanto, que outro artista envolvido no processo apresente um workshop. 
guntas como ferramentas na construção de uma dramaturgia, é o processo criativo do Tanztheater Wuppertal, dirigido pela coreógrafa e bailarina alemã Pina Bausch.

Um dos primeiros passos tomados por Pina Bausch na criação de uma obra é a elaboração de perguntas ou palavras-chave associadas ao tema principal do trabalho, que servirão como molas propulsoras da criação. ${ }^{6}$ Se lermos apenas as palavras-chave ou as perguntas formuladas no processo de criação de alguns espetáculos do Tanztheater, ficaremos sem saber ao certo qual o tema da obra, pois a abordagem de Bausch acontece tangencialmente, buscando aquilo que está no entorno ou na atmosfera sugerida pelo assunto principal. A título de exemplo, recolhemos algumas palavras-chave extraídas do processo de criação do espetáculo Café Müeller, de 1978: "uma planta de amor; lembrar-se, mover-se, tocar-se; despir-se, ficar de frente; escorregar sobre o corpo de um outro; procurar o que está perdido; a proximidade; não saber o que fazer para agradar" (Hodge, 1987, p. 69). Já em Bandoneon, espetáculo de 1980, foram colocadas as seguintes perguntas: "como é possível que alguém combine com você? $\mathrm{O}$ que vocês observam nas crianças e bebês e lamentam terem desaprendido? Que animal você acha erótico e por que? $\mathrm{O}$ que vocês desejariam se pudessem recomeçar outra vez?" (idem, 1989, p. 21).

Depois da proposta, cada bailarino deve responder às perguntas e às palavras-chave com uma cena. Pode agir livremente, utilizando ou não movimentos de dança, músicas, textos, objetos ou a participação de outros bailarinos. Segundo Hoghe, critérios como certo ou errado não tem nenhuma importância nesse processo, pois Bausch incentiva cada bailarino a se posicionar individualmente com liberdade, sem qualquer tipo de censura (idem).

$\mathrm{O}$ mesmo tratamento pode ser percebido na maneira como Antônio Araújo encaminhou os workshops do Teatro da Vertigem em Apocalipse 1, 11.7 Numa reunião que precedeu o início dos encontros, a orientação do diretor era para que os atores não rejeitassem nenhuma idéia, respeitando a primeira imagem ou impulso encontrados, sem julgar o valor de sua produção. $\mathrm{O}$ interesse estava no que trouxessem de consciente e inconsciente em sua formação, suas fantasias e seus desejos em torno das idéias e das imagens sugeridas ou expressas no texto bíblico do Apocalipse de João, uma das fontes do trabalho.

Do ponto de vista do ator do Vertigem, pode-se dizer que o workshop é a atividade que melhor potencializa as qualidades do depoimento artístico autoral. Pois cada palavra ou pergunta deve ser trazida para o campo pessoal do ator, e associada a algum fato de sua vida ou de sua experiência. Dessa maneira, um enunciado de caráter geral, como $O \mathrm{Mal}$ ou $O$ Todo Poderoso, por exemplo, pode ser transferido para uma escala íntima e sintetizado a partir do ponto de vista individual. Há também casos em que o enunciado já é colocado de maneira pessoal, como acontece nas perguntas "o que é o apocalipse para você?" ou "o que você gostaria de dizer enquanto artista?”, que permearam a criação de Apocalipse 1,11.

Apesar de seu caráter aberto, para o Teatro da Vertigem, o workshop deve respeitar alguns critérios internos. Em primeiro lugar, todo ator deve apresentar uma resposta/cena, mesmo que seja apenas um esboço, pois isso reflete o compromisso de cada um frente ao grupo. Em

6 Durante o processo de criação e produção de um espetáculo, que dura em média de dois a três meses, são lançadas para o elenco mais de cem perguntas.

$7 \quad$ Nos referimos aqui a Araújo por ter sido uma figura permanente dos três trabalhos do grupo. Fica implícito que, no caso de Apocalipse 1,11, Fernando Bonassi colaborou na formulação das perguntas e temas. 
seguida, tenta-se evitar ao máximo o didatismo, procurando sempre uma metáfora para representar uma idéia. A respeito desse assunto, Antônio Araújo faz o seguinte comentário: "A idéia é um princípio, não um fim. $\mathrm{O}$ ator deve procurar a tradução artística para a idéia. Quando ela é explicada ou dita ela empobrece a cena. Tenho uma idéia, muito bem, mas como ela se traduz sensivelmente, com jogo, com teatro?”. ${ }^{8}$

Pensando nas respostas/cena oferecidas pelos atores às questôes propostas no workshop, é possível relacionar o processo do Tanztheater ao do Teatro da Vertigem, questionando o que as perguntas formuladas nos dois casos podem ter em comum. O que se percebe é que, em ambos os grupos, há uma valorização das experiências vitais e do arquivo histórico de cada indivíduo. Nesse sentido, as perguntas sempre funcionam como evocações, espécies de chamamentos ao depoimento pessoal.

Numa entrevista com Leonetta Bentivoglio (1986), Pina Bausch afirma que essa característica, tão marcante em seu trabalho, de reconhecer o que há de pessoal e particular em cada bailarino, deve-se a Kurt Jooss, seu antigo mestre. O que alimentava o trabalho de Joss era o interesse pela personalidade singular de cada dançarino, que servia como material de criação do espetáculo. Procedendo da mesma forma, Bausch defende a idéia de que o teatro é o espaço das subjetividades e das recordações. Mas, ao contrário do que se possa imaginar, não interessa à artista apenas a história pessoal do bailarino. As recordações trazidas à cena servem como iscas de recordaçôes coletivas.

Também no Vertigem, o sujeito é peça imprescindível na formação do discurso cênico, pois é exatamente a pluralidade de posicio- namentos que gera o confronto de idéias e vai garantir a qualidade do material de base. A diversidade é, portanto, um dos critérios mais relevantes na produção de materiais.

Essa diversidade também aparecia na dinâmica dos ensaios, acionada pelo intenso cronograma de criação de Apocalipse 1,11, que resultou na produção de mais de 540 cenas, apenas no período inicial dos encontros. A produção diária e contínua de workshops, estudos e improvisações fazia com que os atores se sentissem num permanente brainstorm, um fluxo contínuo de criação em que a sensação de transbordamento não dizia respeito apenas ao excesso de material produzido, mas também ao alargamento daquilo que pode ser considerado o tempo padrão de uma produção teatral. Os ensaios da peça se estenderam por mais de um ano.

Nesse longo processo, era natural que a produção diária e contínua de workshops resultasse em material bastante heterogêneo, com cenas triviais misturadas a outras com traço pessoal bastante forte. Não havia como garantir a qualidade dos workshops. Algumas perguntas ecoavam na hora, outras não tinham resposta, a não ser minutos antes da apresentação. Possivelmente essa alternância se deva tanto à qualidade das perguntas quanto à suscetibilidade do elenco. E é uma oscilação que parece não dizer respeito apenas ao trabalho do Vertigem. Pina Bausch, por exemplo, reconhece uma flutuação semelhante em seu processo e afirma que boas perguntas nem sempre dão bons resultados, o que a leva, por vezes, a reformular uma mesma questão, apresentando-a de maneira totalmente diferente (Schmidt, 1983, p. 235). O mesmo aconteceu no processo de Apocalipse 1,11, pois nem sempre os atores apresentaram as respostas almejadas. ${ }^{9}$

8 Fala registrada no caderno de ensaio da autora e datada de 19.12.1999.

9 Fernando Bonassi, em entrevista realizada pela autora em 17.02.1999, relata: "Juntamente com o Antônio Araújo, nós selecionamos temas para improvisações. Por mais que tenhamos escolhido, o material que os atores trouxeram nem sempre correspondia aquilo que nós imaginávamos". 


\section{Ator-autor: depoimento pessoal}

Foi na tentativa de estabelecer um novo patamar para o ator em processo colaborativo que se fez necessária a criação de um nome. Em sua dissertação de mestrado, Antônio Araújo sugere ator-pensador, ou ainda a(u)tor (Araújo Silva, 2002, p. 84). Poderíamos chamá-lo ainda de ator-criador, no esforço de aproximá-lo da idéia de um artista autônomo, que participa da obra como um todo. Porém, tal termo parece ainda não traduzir com precisão a participação do ator como co-autor do texto escrito e do espetáculo.

A idéia de um ator que fala e age com voz própria nos remete ao conceito do performer. Se, como afirma Cohen, "o performer vai representar partes de si mesmo e de sua visão de mundo" (Cohen, 2002, p. 106), há uma estreita afinidade entre tal pensamento e o lugar almejado pelo ator do Teatro da Vertigem. Assim como o performer, ele também é criador e intérprete de sua obra.

JoAnne Akalaitis, diretora do grupo Mabou Mines, também propõe uma relação de parceria com os atores, usando o termo $\mathrm{em}$ powered para se referir ao ator "intelectual, espiritual, flexível e colaborativo". Segundo a encenadora, "dar autoridade a atores é estar interessado naquilo em que eles estão interessados e em quem eles são como pessoas; e recusar-se a ser condescendente ou infantilizá-los" (Saivetz, 2000, p. 36).

Essa idéia de Akalaitis surgiu de sua prática com o grupo, em que o ator é visto como um criador com autonomia e inteligência, capaz de funcionar dentro e fora do palco. Tal habilidade é descrita pela diretora como um "enorme sentido para a performance". Ela considera o período de seu treinamento com Jerzy Grotowski, no Teatro Laboratório, a maior influência em sua carreira, mudando radicalmente suas idéias e, particularmente, clarificando a noção de que o "ator não é só um intérprete de textos, mas um criador, assim como um pintor, escritor, ou qualquer artista gerador" (Saivetz, 2000, p. 37).

Voltando para o processo do Teatro da Vertigem, foi na busca de uma relação revitalizada com os atores que surgiu a idéia do depoimento pessoal, um dos eixos de criação do grupo. A palavra "depoimento", no seu sentido comum, nos remete à idéia de confissão de um segredo, e também de exposição pública de um testemunho. Ambas as definições, bastante apropriadas à temática bíblica tratada no espetáculo, estão relacionadas na prática do Teatro da Vertigem. De maneira sucinta, o depoimento pessoal é, para o ator, uma qualidade de presença cênica, de expressão de uma visão particular ou de um posicionamento frente à determinada questão. O depoimento é uma qualidade de exposição de si próprio. ${ }^{10}$

Por se tratar de uma expressão comum e pouco específica, talvez seja conveniente nos reportarmos à fala de Araújo, que revela a dupla função do depoimento pessoal, que acaba por deslocar a posição do ator no processo de criação: “o depoimento pessoal não funciona apenas como instrumento de pesquisa - no caso temática mas também como o próprio material bruto de concretização da cena. Além de se constituir em um exercício interpretativo de caráter investigatório, ele também conclama o ator a assumir um papel de autor e criador da cena, construída a partir do material que ele mesmo traz para os ensaios" (Araújo Silva, 2002, p. 84).

Nessa afirmação do diretor, percebemos que o depoimento artístico autoral é uma qualidade de participação e pressupõe um ator propositivo na apresentação de materiais e também reflexivo na condução do processo de criação.

10 Apesar de nosso foco ser o ator no processo colaborativo, é importante apontar que o depoimento pessoal pode se dar em qualquer área de criação. Ele não é exclusividade do trabalho do ator. 
Quando dizemos que o depoimento pessoal é uma qualidade de posicionamento do ator, de sua opinião frente a alguma coisa, pode parecer que se trata de um ator de palanque, com um discurso verbal forte. De fato, não é isso. Muito do material proposto pode nos remeter a sensaçóes a respeito do tema, por vezes com grande poder simbólico, não chegando a uma narrativa linear. $\mathrm{Ou}$, quando acontece de esse material advir da biografia do artista, pode conter uma carga emocional inerente, que participa dessa associação. Outras vezes, o depoimento pode vir da leitura de um texto escrito pelo ator, numa circunstância que aparentemente afasta qualquer emotividade. Portanto, não há uma forma pré-estabelecida para o depoimento.

O que se pode afirmar é que o depoimento artístico autoral exige um campo de amoralidade, onde é permitido expressar-se com liberdade. Antonio Araújo chama tais revelações de "desvelamentos", e o significado do conceito dá à prática do depoimento uma nova dimensão (Araújo Silva, 2002, p. 84). A origem dela está claramente associada às idéias de Jerzy Grotowski, que enfatiza a importância de trazer um "eu" para a performance, diminuindo o espaço existente entre "quem você é" e "o que você representa", na relação entre ator e personagem (Grotowski, 1992 e 1996, p. 78). Para Grotowski, a exposição pessoal é o ato de atingir a própria individualidade e, para tanto, não é necessário aprender coisas novas, mas ao contrário, eliminar barreiras. Trata-se da via negativa de trabalho, a que Lisa Wolford se refere da seguinte forma: "Ao contrário dos programas de treinamento que têm por objetivo dar ao ator um conjunto de habilidades, o objetivo da me- todologia de Grotowski era tirar do ator tudo o que o obstruísse em relação ao movimento, à respiração, e, mais importante, ao contato humano" (Wolford, 2003, p. 200).

Por se tratar de um ato de despudoramento, o depoimento artístico autoral pode ser facilmente associado à idéia de um ator que grita, se debate ou se desnuda em cena. Mas isso tudo pode acontecer sem que ocorra depoimento algum. Não se trata de exibicionismo, mas antes de desarmamento, de um ato de "emergir de si mesmo" que envolve disciplina, a que Grotowski se refere como uma oportunidade responsável (Grotowski, 1992, p. 211).

Diante de tal ato, tem-se a sensação de estar compartilhando de algo único, que merece deferência, pois o que era segredo de um indivíduo passa a ser o segredo de um grupo. A partir daí, forma-se um círculo de proteção em sala de ensaio, que garante o mergulho na criação e estabelece um grau de cumplicidade forte, um pacto de silêncio diante das revelações, como apontado pelo ator Roberto Áudio no processo de Apocalipse 1,11: "Às vezes era muito difícil ver um amigo em tamanha exposição, e, por isso mesmo, me expor ao extremo se tornou uma questão de respeito. [...] Percebi que, a cada dia, o grupo se tornava mais forte à medida que trabalhávamos com nossas fraquezas". ${ }^{11}$

Há uma instância em que o ator do Teatro da Vertigem opera na exposição de seu "eu", conjugando o material da pesquisa com sua visão pessoal e subjetiva. Nessa fase do trabalho, é muito comum que o ator se posicione não pretendendo ser outra coisa senão "ele próprio", o performer. ${ }^{12}$ Porém, no resultado cênico percebemos que ele se comporta, age e fala como

11 Os atores do Teatro da Vertigem. "O que fazemos em sala de ensaio". Em: Teatro da Vertigem, op. cit., p. 47.

12 "O performer é aquele que fala em seu próprio nome, enquanto artista e pessoa, e como tal se dirige ao público ao passo que o ator representa sua personagem" (Pavis, 2001, p. 284). 
sendo um "outro", o ator. ${ }^{13} \mathrm{O}$ que acontece, portanto, na passagem entre o material bruto do workshop e a cena acabada do espetáculo?

Imbuído do material de leitura e sob a influência dos procedimentos em sala de ensaio, o ator participa da criação da obra colaborando com textos, falas, imagens, gestos, intervenções no espaço, figurinos, desenhos de luz, sugestôes musicais e personagens. Os materiais de sua criação são apresentados e se desenvolvem no espaço propositivo da cena e a idéia da personagem nasce da experiência dos ensaios, como resultado de um mergulho interno. $\mathrm{O}$ que se percebe é que o ator se alimenta da realidade para buscar em si mesmo as ressonâncias dela, num processo que Renato Cohen considera mais caracterizado pela "extrojeção - tirar coisas de si -, do que pela introjeção - receber a personagem" (Cohen, 2002, p. 105).

Contudo, o longo percurso que vai do workshop à cena está pleno de materiais que vão se sobrepondo e transformando o material bruto do workshop numa ação complexa, conseqüência de muitas camadas dramatúrgicas. Dessa forma, por mais que um ator apresente-se como "ele próprio", sem nenhuma intenção de ser "um outro", no transcorrer dos ensaios esse "eu" vai se distanciando, ou melhor, projetandose para se constituir em um "eu personagem". ${ }^{14}$

Um dos fatores que implica na subjetivação das personagens nos espetáculos do Teatro da Vertigem se deve ao fato de que, ao interpretar uma dramaturgia convencional, o ator recria a personagem por meio das palavras escritas e das ações descritas nas rubricas pelo autor do texto. Em Apocalipse 1,11 aconteceu o inverso: o texto cênico adquiriu forma literária ao longo da pesquisa. ${ }^{15}$ Apesar de terem como ponto de partida as figuras e as alegorias bíblicas, as personagens do espetáculo não tinham uma pré-existência literária, anterior à sua forma cênica. $O$ processo de criação delas estava intimamente ligado ao repertório pessoal de cada ator, confundindo figura e fundo, o "eu" e o "outro". Uma vez apresentadas ao público, tornaram-se criações autônomas, em que o "eu" do ator se tornava o "eu" da personagem. ${ }^{16}$

A performer Marina Abramovic considera essa diferenciação entre a autobiografia e uma perspectiva mais geral como inerente ao seu

13 Sobre a distinção entre o "eu" e o "outro", performance e teatro, Marvin Carlson fala de forma bastante clara: "Apesar do teatro tradicional ter considerado o 'outro' como uma personagem da ação dramática, encarnado (por meio da representação) por um ator, a arte da performance moderna, em geral, não está preocupada com essa dinâmica. Seus profissionais, quase por definição, não baseiam seu trabalho em personagens previamente criados por outro artista, mas em seus próprios corpos, suas próprias autobiografias, suas próprias experiências específicas numa cultura e num mundo, transformados em elementos de performance por meio da consciência deles próprios num processo de mostrarem-se para um público" (Carlson, 2002, p. 150).

14 No texto "Restoration of behavior", Richard Schechner afirma que qualquer tipo de performer apresenta a recuperação de um comportamento, mesmo que seja a recuperação daquilo que ele pensa ser "si mesmo" (Schechner, 2003, p. 28).

15 Josette Féral, ao analisar o texto "Treinamento intercultural", de Richard Schechner, traduz o termo "texto de representação" [performance text] para "texto performático" [texte performatif], ou seja, um texto indissociável de sua forma cênica (cf. Féral, 1999).

16 Esse procedimento fica bastante claro na personagem Talidomida do Brasil, por exemplo, que nasce de elementos autobiográficos da atriz Mariana Lima. Se essa criação fosse estritamente expressão do "eu" de Mariana, a interpretação dessa personagem, ou figura, ficaria comprometida se realizada por um outro ator. 
processo criativo: "Todo verdadeiro artista é meio assim. Eu penso que você tem que chegar a uma síntese. Você sempre deve começar de você mesmo, mas no processo o resultado que vem ao público deve ser transcendental e geral. Ele deve tornar-se de todo mundo. Mas começa com o pessoal, sempre. [...] Então, quão mais fundo você mergulha em si mesmo, na verdade, mais universal você parece" (Kaye, 2002, p. 21).

Em outras palavras, se um ator do "Vertigem" apresenta uma personagem que se pareça com ele mesmo, quando mostra essa personagem ao público suas características passam a funcionar como parte constituinte do caráter ficcional dessa personagem. Se acontecer de um outro ator ter que assumir essa personagem, poderá modificar seu desenho, mas não alterará aquilo que ela representa, nem suas qualidades essenciais.

Talvez a palavra "personagem" possa parecer inapropriada em se tratando dos seres ficcionais de Apocalipse 1,11. Seja pela sua natureza impura, conseqüência das múltiplas contribuições no processo colaborativo, seja pelos "contornos incertos" 17 que apresentam no resultado cênico, ou por sua reticente função narrativa, tais "criaturas" 18 parecem estar distantes da concepção de personagem da dramaturgia tradicional. Mas ainda assim são tidas como "um outro", estejam fora ou dentro "de mim".

17 Termo utilizado por Ryngaert, 2003, p. 11.

18 Jean-Pierre Ryngaert comenta Abirached, que baseado na retórica latina, usa três palavras para definir a personagem: persona, character e typus (Ryngaert, 2003, p. 12). 


\section{Referências bibliográficas}

ARAÚJO SILVA, A. C. de. "A gênese da Vertigem: o processo de ciação de O Paraíso Perdido". Dissertação de Mestrado, 2002.

BENTIVOGLIO, L. "Une conversation avec Pina Bausch". In: DELAHAYE, G. Pina Bausch. Paris: Solin, 1986.

CARLSON, M. "What is performance". In: Huxley, M. \& Witts, N. The twentieth-century. Performance Reader. New York: Routledge, 2002.

COHEN, R. A performance como linguagem. São Paulo: Perspectiva, 2002, p. 106.

FÉRAL, J. "Le texte spetaculaire: la scène et son texte". In: Degrés. Revue de Synthèse à Orientation Sémiologique, n. 97-98-99, 1999, p. 1-21.

GROTOWSKI, J. Em busca de um teatro pobre. Rio de Janeiro: Civilização Brasileira, 1992.

"El Performer". In: Máscara - Caderno iberoamericano de reflexion sobre escenologia. México, n. 11-12, ano 3, 1992 e 1996.

HODGE, R. \& WEISS, U. Bandoneon. Em que o tango pode ser bom para tudo? Attar Editorial: São Paulo, 1989.

HODGE, R. Pina Bausch. Histoires de théâtre dansé. Paris: L'Arche, 1987.

KAYE, N. "Marina Abramovic. Interview”. In: HUXLEY, M. \& WITTS, N. The twentieth-century-Performance Reader. New York: Routledge, 2002.

PAVIS, P. Dicionário de teatro. São Paulo: Perspectiva, 2001.

RYNGAERT, J.P. “Incarner des fantômes qui parlent". In: L'acteur entre personnage et performance. Belgique: Études Thèâtrales, 2003.

SAIVETZ, D. An event in space. JoAnne Akalaitis in rehearsal. New Hampshire: Smith and Kraus, 2000.

SCHECHNER, R. Performance studies. New York: Routledge, 2003.

SCHMIDT, J. "Pina Pausch: Interview with the Wuppertal Choreographer". In: Ballett International, 6, n. 2, 1983.

WOLFORD, L. "Grotowski vision of the actor". In: HODGE, A. Twentieth Century Actor Training, New York: Routledge, 2003. 